\title{
Method for kinetic studies of urea and ammonia net transfer across the rumen wall of sheep
}

\author{
D Rémond, JP Chaise, E Delval, J Lefaivre
}

INRA Theix, laboratoire de la Dynamique de la digestion, 63122 Saint-Genes-Champanelle, France

Nitrogen movement across the rumen epithelium has been commonly investigated with tracer techniques requiring steadystate conditions. No information is available on kinetic aspects of urea and ammonia net transfer across the rumen wall of sheep fed twice daily. We report here an experimental approach allowing continuous measurement of meal-related nitrogen exchange variations.

Two wk before the experiments, chronic catheters (silicone rubber) were surgically implanted in both ruminal veins (just before they join the gastrosplenic vein) and in a mesenteric artery. Flowprobes (Transonic System Inc, New York) were implanted on both ruminal arteries for total ruminal blood flow measurement. Eight Texel wethers $(69-71 \mathrm{~kg})$ were prepared in this manner and all catheters remained functional during sampling periods (2-3 months).

Post-mortem examination displayed no vascular traumatism due to catheters or flowprobe implantation. The net whole blood exchange of urea and $\mathrm{NH}_{3}$ across the rumen wall was calculated by combining arteriovenous differences and blood flow according to the equation proposed by Early et al (1987). The kinetics of urea and ammonia net transfer could then be plotted, and integrated to provide the daily quantities transferred across the rumen wall. The preliminary results obtained using this technique were consistent with those found in the literature. For example, for sheep fed 2 meals per $d$ at 12 -h intervals with orchard grass hay $(430 \mathrm{~g} \mathrm{DM} /$ meal: $611 \mathrm{~g} \mathrm{DOM}$ and $23.6 \mathrm{~g} \mathrm{~N} / \mathrm{kg} \mathrm{DM}$ ), $1.9 \mathrm{~g}$ urea- $\mathrm{N} / \mathrm{d}$ and $3.4 \mathrm{~g} \mathrm{NH}_{3}-\mathrm{N} / \mathrm{d}$ were transferred across the epithelium; the addition of 240 or $480 \mathrm{~g}$ of wheat starch to the daily ration raised urea net transfer to 3.9 and $4.7 \mathrm{~g} \mathrm{~N} / \mathrm{d}$ respectively (means for 3 sheep, 1 repetition), and altered the daily balance of urea and ammonia exchange from a loss to a gain in nitrogen for the rumen.

In conclusion, this method provides direct and instantaneous measurements of nutrient movement across the rumen epithelium of sheep, allowing quantitative study of nutrient absorption from and secretion into the rumen.

Early RJ, Thompson JR, Christopherson RJ, Sedgwick GW (1987) Can J Anim Sci 67, 1011-1020 